\title{
Effect of IFKhAN-92 inhibitor on electrode reactions and corrosion of mild steels in hydrochloric and sulfuric acid solutions
}

\author{
Ya. G. Avdeev* and A. Yu. Luchkin \\ A. N. Frumkin Institute of Physical Chemistry and Electrochemistry, Russian Academy \\ of Sciences, Leninskii pr. 31, Moscow, 119071 Russian Federation \\ *E-mail: avdeev@kspu.kaluga.ru
}

\begin{abstract}
Studies on the effect of inhibitor formulations based on IFKhAN-92 on the electrode reactions of mild steel in hydrochloric and sulfuric acid solutions have shown that these formulations considerably hinder the cathodic and anodic reactions on the metal at temperatures at least up to $100^{\circ} \mathrm{C}$. This result allowed us to assume that it is possible to slow down steel corrosion efficiently by formulations based on IFKhAN-92 not only below $100^{\circ} \mathrm{C}$ but also at higher temperatures, as confirmed by corrosion tests in hydrochloric acid (up to $160^{\circ} \mathrm{C}$ ) and sulfuric acid (up to $200^{\circ} \mathrm{C}$ ).
\end{abstract}

Key words: acid corrosion, corrosion inhibitor, mild steel, triazole.

Received: February 8, 2013

doi: $\underline{10.17675 / 2305-6894-2013-2-1-053-066}$

Triazole derivatives find increasing application in studies of organic compounds for the protection of metals in acid solutions [1,2]. Among compounds of this class, IFKhAN-92 deserves attention, as it efficiently inhibits the corrosion of mild steels [3], high strength steels [4], and stainless steels [5], as well as non-ferrous metals [6], in mineral acid solutions. It has been proven that IFKhAN-92 and mixtures based on it can be used to protect steel in mineral acid solutions at elevated temperatures, $t>100^{\circ} \mathrm{C}$ [7]. We have found that the high efficiency of IFKhAN-92 in the inhibition of mild steel corrosion in $\mathrm{HCl}$ and $\mathrm{H}_{2} \mathrm{SO}_{4}$ solutions is due to the formation of a protective polymolecular layer chemically bound to the metal surface [8].

In order to get a better understanding of the protective nature of IFKhAN-92 on the corrosion of mild steel in mineral acid solutions, it is expedient to determine the effect of this inhibitor and its mixtures on the electrode reactions of the metal in a broad temperature range and to compare the data obtained with the results on metal corrosion rates obtained by the mass loss method.

\section{Experimental}

Electrochemical measurements were carried out at $t=20-100^{\circ} \mathrm{C}$ using a static cylindrical electrode made of steel $20\left(0.72 \mathrm{~cm}^{2}\right)$ in $2.0 \mathrm{M} \mathrm{HCl}$ and $\mathrm{H}_{2} \mathrm{SO}_{4}$ solutions deaerated with argon. The steel electrode potentials were measured against a silver chloride electrode and converted to the normal hydrogen scale. An electrode preliminarily cleaned with emery 
paper M20 and degreased with acetone was kept for $30 \mathrm{~min}$ in the solution being studied, then an IPC-PRO MF potentiostat was used to record anodic and cathodic polarization curves successively at a potentiodynamic sweep rate of $0.0005 \mathrm{~V} / \mathrm{s}$.

Corrosion tests were carried out using $20 \mathrm{~mm} \times 20 \mathrm{~mm} \times 3 \mathrm{~mm}$ steel 20 specimens in $2.0 \mathrm{M} \mathrm{HCl}$ and $\mathrm{H}_{2} \mathrm{SO}_{4}$ solutions. The specimens were cleaned on an abrasive disc (ISO 9001, 60 grit) and degreased with acetone prior to each experiment. The test duration was $30 \mathrm{~min}$. The tests at $t=0-100^{\circ} \mathrm{C}$ were carried out in temperature-controlled corrosion vessels using the conventional technique.

High-temperature corrosion tests $\left(t=120-200^{\circ} \mathrm{C}\right)$ were carried out in an autoclave manufactured by Huber (Finland) (the accuracy of temperature control was $\pm 3^{\circ} \mathrm{C}$ ). The autoclave tests were carried out as follows. A specimen was placed in a quartz autoclave vessel containing $100 \mathrm{ml}$ of $2.0 \mathrm{M} \mathrm{HCl}$ or $\mathrm{H}_{2} \mathrm{SO}_{4}$ solution. The vessel was heated to the required temperature, kept for $40 \mathrm{~min}$ at that temperature, and cooled to $104^{\circ} \mathrm{C}$. In order to take the specimen mass loss during autoclave heating and cooling into account, the tests were duplicated with exposure at the corresponding temperatures for $10 \mathrm{~min}$. The corrosion rate for a 30 min period was calculated from the difference between the specimen mass loss after a 40-minute exposure in the autoclave at the corresponding $t$ and the mass loss after the 10-minute exposure.

Due to the low solubility of IFKhAN-92, it was added to $\mathrm{HCl}$ and $\mathrm{H}_{2} \mathrm{SO}_{4}$ solutions as a solution in ethanol. The resulting ethanol concentration in the pickling solution was $0.24 \mathrm{~mol} / \mathrm{l}$.

The efficiency of inhibitors was estimated from the inhibition coefficient, $\gamma=k_{0} / k_{\text {in }}$, and the degree of protection $Z=\left[\left(k_{0}-k_{\text {in }}\right) / k_{0}\right] \cdot 100 \%$, where $k_{0}$ and $k_{\text {in }}$ are the corrosion rates in the non-inhibited solution and in the solution with the additive being studied, respectively.

In order to estimate quantitatively the effect of additives on inhibitors, the mutual influence coefficients of the mixture components were calculated [9]:

$$
K_{m}=\frac{\gamma_{m i x}}{\prod_{i=1}^{m} \gamma_{i}}
$$

where $\gamma_{\text {mix }}$ is the corrosion inhibition coefficient for the inhibitor mixture and $\prod_{i=1}^{m} \gamma_{i}$ is the product of the corrosion inhibition coefficients for the individual mixture components. If $K_{m}<1$, the protective effect of the inhibitor components is mutually reduced; at $K_{m}=1$, it has an additive nature; and it is only at $K_{m}>1$ that a mutual enhancement of protection by the mixture components is observed. 


\section{Experimental results and discussion}

\section{Electrochemical studies}

\section{Hydrochloric acid}

The free corrosion potential $\left(E_{\text {cor }}\right)$ of a steel electrode in the reference solution $(2.0 \mathrm{M} \mathrm{HCl})$ is nearly independent of temperature (Table 1, Fig. 1). In all the temperature range studied, the slope of anodic polarization is much higher than the value of $0.060 \mathrm{~V}$ predicted by theory [10]. We attribute this to the formation of a visible sludge layer on the metal surface during the $30 \mathrm{~min}$ exposure at $E_{\text {cor }}$ followed by anodic polarization. The layer partially shields the steel surface and creates diffusion hindrance to the movement of the reagents to the metal surface or removal of the reaction products. The slope of cathodic polarization at $t \leq 60^{\circ} \mathrm{C}$ matches the theoretical value of $0.120 \mathrm{~V}$ [10]. However, a limiting diffusion current $\left(i_{\mathrm{d}}\right)$ is observed at higher temperatures, which is a result of sludge present on the metal surface and abundant evolution of gaseous hydrogen that shields the surface. An increase in $t$ results in a consistent increase in cathodic and anodic currents, but, starting from $t=80^{\circ} \mathrm{C}$, the electrode reaction rates grow much more slowly. Apparently, sludge formation and evolution of gaseous hydrogen on the metal surface are accelerated with an increase in $t$ and this slow down the electrode processes. The higher the $t$ value, the more significant the effect of sludge formation and gas evolution on the electrode reactions of steel becomes.

In the presence of $5.0 \mathrm{mM}$ IFKhAN-92 $\left(t=20-80^{\circ} \mathrm{C}\right), E_{\text {cor }}$ is higher by 0.040 $0.065 \mathrm{~V}$ than in the reference solution, which indicates that the inhibitor preferentially hinders the anodic reaction of steel. In the presence of $5.0 \mathrm{mM}$ IFKhAN-92, the slope of steel anodic polarization is rather high in the range from $0.090 \mathrm{~V}$ to $i_{\mathrm{d}}$. The $b_{\mathrm{a}}$ values obtained $\left(t \leq 80^{\circ} \mathrm{C}\right)$ are somewhat lower than those for the reference solutions but considerably higher than the $b_{\mathrm{a}}$ values predicted by theory. The increase in $b_{\mathrm{a}}$ of steel electrode in the presence of IFKhAN-92 is due to the formation of a protective film on steel that hinders the anodic process considerably. In this case, the sludge formation on the surface should be minimized because the inhibitor slows down steel dissolution. The $b_{\mathrm{c}}$ slope in the presence of $5.0 \mathrm{mM}$ IFKhAN-92 matches the limiting diffusion current, most likely due to the formation of a protective film by the inhibitor. At $t \leq 80^{\circ} \mathrm{C}$, addition of $5.0 \mathrm{mM}$ of the inhibitor decreases the cathodic $\left(Z_{\mathrm{c}}=93.2-99.4 \%\right)$ and anodic currents $\left(Z_{\mathrm{a}}=\right.$ 98.4-99.2\%). However, as the temperature is increased from 80 to $100^{\circ} \mathrm{C}$, the hindrance of the electrode reactions by the inhibitor decreases abruptly: $\gamma_{\mathrm{c}}$ decreases 12.8 -fold and $\gamma_{\mathrm{a}}$ decreases 7.8-fold. A study of the effect of $C_{\text {IFKhAN-92 }}$ on the electrode reactions $\left(t=60^{\circ} \mathrm{C}\right)$ has shown that the hindrance of both of them by the inhibitor increases with an increase in its content in solution, and that the most efficient hindrance $(Z \geq 99 \%)$ occurs at $C_{\text {IFKhAN-92 }} \geq$ $5.0 \mathrm{mM}$. 
Table 1. Free corrosion potentials $\left(E_{\mathrm{cor}}\right)$, Tafel slopes $b_{\mathrm{c}}$ and $b_{\mathrm{a}}$, cathodic and anodic current densities $\left(i_{\mathrm{c}}\right.$ and $i_{\mathrm{a}}$ ), and inhibition coefficients for the cathodic and anodic reactions $\left(\gamma_{\mathrm{c}}\right.$ and $\left.\gamma_{\mathrm{a}}\right)$ of a steel cylinder in $2.0 \mathrm{M} \mathrm{HCl}$ as a function of $t$ at $E=-0.300$ and $-0.100 \mathrm{~V}$, respectively.

\begin{tabular}{|c|c|c|c|c|c|c|c|c|}
\hline Inhibitor & $t,{ }^{\circ} \mathrm{C}$ & $E_{\mathrm{corr}}, \mathrm{V}$ & $b_{c}, \mathbf{V}$ & $b_{\mathrm{a}}, \mathrm{V}$ & $i_{c}, \mathbf{A} / \mathbf{m}^{2}$ & $i_{\mathrm{a}}, \mathbf{A} / \mathbf{m}^{2}$ & $\gamma_{c}$ & $\gamma_{\mathrm{a}}$ \\
\hline- & & -0.220 & 0.120 & 0.110 & 9.74 & 40.7 & - & - \\
\hline $5.0 \mathrm{mM}$ IFKhAN-92 & & -0.170 & $i_{\mathrm{d}}$ & 0.090 & 0.66 & 0.65 & 14.8 & 62.6 \\
\hline $5.0 \mathrm{mM} H A$ & 20 & -0.220 & 0.120 & 0.090 & 8.19 & 19.9 & 1.2 & 2.1 \\
\hline $\begin{array}{l}2.5 \text { mM IFKhAN-92 } \\
+2.5 \text { mM HA }\end{array}$ & & -0.130 & $i_{\mathrm{d}}$ & 0.090 & 1.28 & 0.27 & 7.6 & 150 \\
\hline- & & -0.235 & 0.120 & 0.120 & 142 & 223 & - & - \\
\hline $5.0 \mathrm{mM}$ IFKhAN-92 & & -0.170 & $i_{\mathrm{d}}$ & 0.090 & 1.90 & 1.94 & 74.7 & 115 \\
\hline $5.0 \mathrm{mM} \mathrm{HA}$ & 40 & -0.220 & 0.120 & 0.090 & 58.2 & 233 & 2.4 & 0.96 \\
\hline $\begin{array}{l}2.5 \text { mM IFKhAN-92 } \\
+2.5 \text { mM HA }\end{array}$ & & -0.165 & $i_{\mathrm{d}}$ & 0.090 & 1.55 & 1.97 & 91.6 & 113 \\
\hline- & & -0.235 & 0.120 & $i_{\mathrm{d}}$ & 400 & 618 & - & - \\
\hline $0.1 \mathrm{mM}$ IFKhAN-92 & & -0.225 & 0.120 & 0.090 & 188 & 95.0 & 2.1 & 6.5 \\
\hline $1.0 \mathrm{mM}$ IFKhAN-92 & & -0.200 & 0.120 & 0.090 & 127 & 41.7 & 3.2 & 14.2 \\
\hline $5.0 \mathrm{mM}$ IFKhAN-92 & & -0.180 & $i_{\mathrm{d}}$ & 0.090 & 3.59 & 5.70 & 111 & 108 \\
\hline $\begin{array}{c}10.0 \mathrm{mM} \text { IFKhAN- } \\
92\end{array}$ & 60 & -0.170 & $i_{\mathrm{d}}$ & 0.090 & 2.18 & 5.65 & 184 & 111 \\
\hline $5.0 \mathrm{mM} \mathrm{HA}$ & & -0.220 & 0.120 & 0.090 & 240 & 643 & 1.7 & 0.96 \\
\hline $\begin{array}{c}2.5 \mathrm{mM} \text { IFKhAN-92 } \\
+2.5 \mathrm{mM} \mathrm{HA}\end{array}$ & & -0.190 & $i_{\mathrm{d}}$ & 0.090 & 2.09 & 4.8 & 191 & 128 \\
\hline- & & -0.220 & $i_{\mathrm{d}}$ & $i_{\mathrm{d}}$ & 1652 & 2730 & - & - \\
\hline $5.0 \mathrm{mM}$ IFKhAN-92 & & -0.180 & $i_{\mathrm{d}}$ & 0.110 & 35.0 & 21.0 & 47.2 & 130 \\
\hline $5.0 \mathrm{mM} H A$ & 80 & -0.220 & $i_{\mathrm{d}}$ & $i_{\mathrm{d}}$ & 861 & 1668 & 1.9 & 1.7 \\
\hline $\begin{array}{c}2.5 \mathrm{mM} \text { IFKhAN-92 } \\
+2.5 \mathrm{mM} \mathrm{HA}\end{array}$ & & -0.220 & $i_{\mathrm{d}}$ & 0.120 & 9.8 & 15.3 & 169 & 178 \\
\hline- & & -0.220 & $i_{\mathrm{d}}$ & $i_{\mathrm{d}}$ & 2427 & 3735 & - & - \\
\hline $5.0 \mathrm{mM}$ IFKhAN-92 & & -0.210 & $i_{\mathrm{d}}$ & $i_{\mathrm{d}}$ & 651 & 225 & 3.7 & 16.6 \\
\hline $5.0 \mathrm{mM} \mathrm{HA}$ & & -0.220 & $i_{\mathrm{d}}$ & $i_{\mathrm{d}}$ & 1310 & 2348 & 1.9 & 1.6 \\
\hline $\begin{array}{c}2.5 \text { mM IFKhAN-92 } \\
+2.5 \text { mM HA }\end{array}$ & 100 & -0.220 & $i_{\mathrm{d}}$ & $i_{\mathrm{d}}$ & 83.7 & 80.0 & 29.0 & 46.7 \\
\hline $\begin{array}{l}5.0 \mathrm{mM} \text { IFKhAN-92 } \\
+10.0 \mathrm{mM} \mathrm{HA}\end{array}$ & & -0.220 & $i_{\mathrm{d}}$ & $i_{\mathrm{d}}$ & 63.5 & 53.4 & 38.2 & 69.9 \\
\hline
\end{tabular}




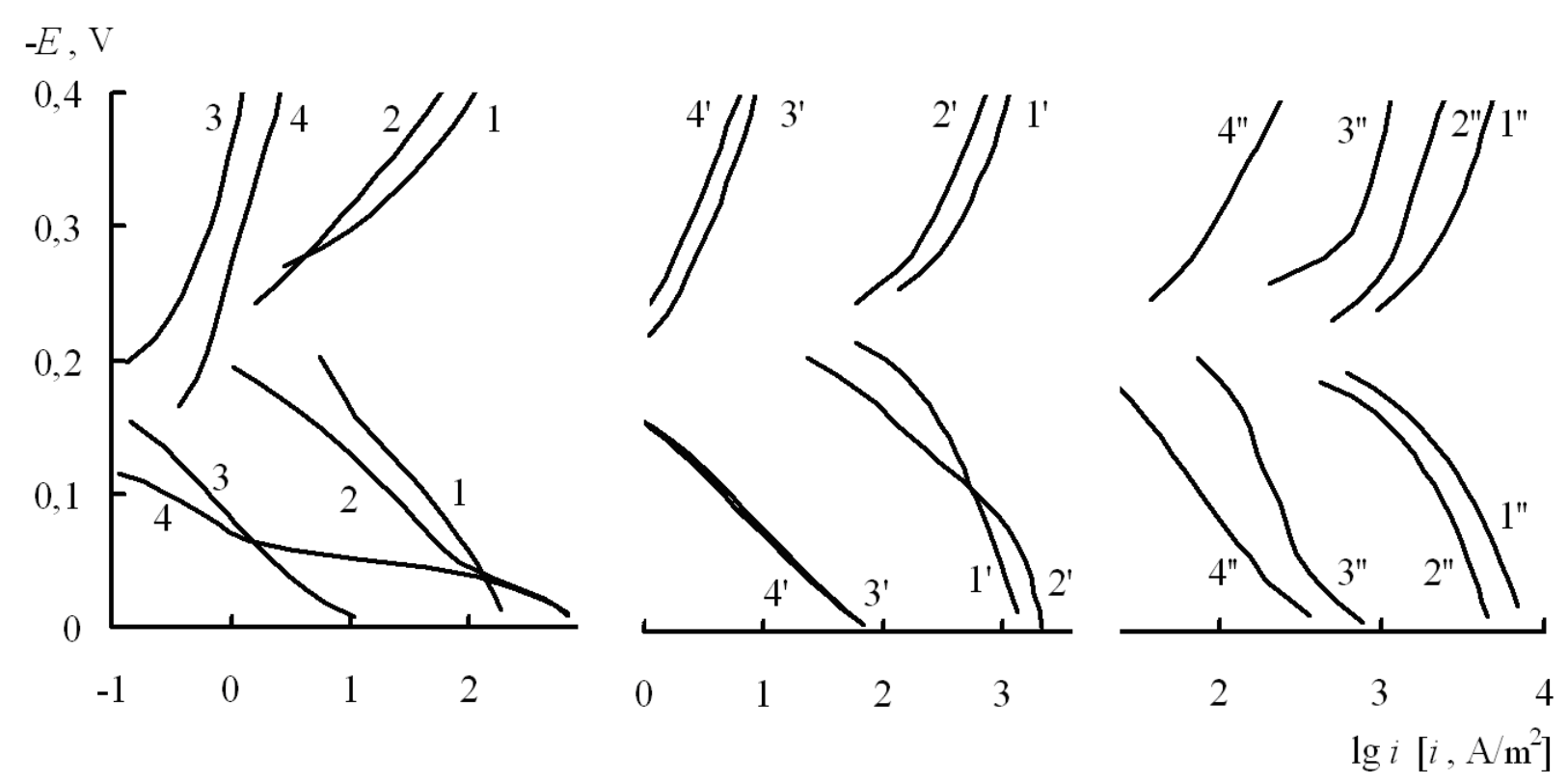

Fig. 1. Polarization curves of a steel cylinder in $2.0 \mathrm{M} \mathrm{HCl}\left(1, l^{\prime}, l^{\prime \prime}\right)$ containing $5.0 \mathrm{mM}$ HA (2, 2', 2''), 5.0 mM IFKhAN-92 (3, 3', 3''), or 2.5 mM IFKhAN-92 + 2.5 mM HA (4, 4', 4') at temperatures, ${ }^{\circ} \mathrm{C}: 25-1,2,3,4 ; 60-1^{\prime}, 2^{\prime}, 3^{\prime}, 4^{\prime} ; 100-1^{\prime \prime}, 2^{\prime \prime}, 3^{\prime \prime}, 4^{\prime \prime}$.

Thus, according to electrochemical data, the IFKhAN-92 inhibitor should protect mild steel at $t \leq 80^{\circ} \mathrm{C}$, but its protective effect should decrease at higher temperatures. One of the ways to enhance the efficiency of acid corrosion inhibitors is to create formulations on their basis. In $\mathrm{HCl}$ solutions, the IFKhAN-92 inhibitor was studied in formulation with a "HA" molecular additive, which by itself does not change $E_{\text {cor }}$ considerably at $C=5.0 \mathrm{mM}$ and slows down the electrode reactions only slightly: $Z_{\mathrm{c}} \leq 58.3 \% ; Z_{\mathrm{a}} \leq 52.4 \%$.

An equimolar mixture of IFKhAN-92 with HA increases $E_{\text {cor }}$ by $0.045-0.090 \mathrm{~V}$ at $t \leq 60^{\circ} \mathrm{C}$, which suggests that the anodic reaction is inhibited preferentially. At higher temperatures, the $E_{\text {cor }}$ of steel in a solution containing a formulation of the inhibitors is the same as that observed in the reference solution. The slopes of cathodic and anodic polarization of steel in $2.0 \mathrm{M} \mathrm{HCl}+2.5 \mathrm{mM}$ IFKhAN-92 $+2.5 \mathrm{mM}$ HA match the values observed in $2.0 \mathrm{M} \mathrm{HCl}+5.0 \mathrm{mM}$ IFKhAN-92, but at $t \geq 60^{\circ} \mathrm{C}$ the anodic and especially cathodic current densities ( $i_{\mathrm{a}}$ and $i_{\mathrm{c}}$, respectively) in a solution containing the composition inhibitor are much lower than those in a solution containing only IFKhAN-92. It is noteworthy that $2.5 \mathrm{mM}$ IFKhAN-92 $+2.5 \mathrm{mM} \mathrm{HA}\left(t=60^{\circ} \mathrm{C}\right)$ hinder both electrode reactions more strongly than IFKhAN-92 with a double concentration. Even at $100^{\circ} \mathrm{C}$, the $i_{\mathrm{c}}$ and $i_{\mathrm{a}}$ values of steel electrode in $2.0 \mathrm{M} \mathrm{HCl}+2.5 \mathrm{mM}$ IFKhAN-92 $+2.5 \mathrm{mM}$ HA are 7.8 and 2.8 times smaller, respectively, than the corresponding parameters of steel in $2.0 \mathrm{M}$ $\mathrm{HCl}+5.0 \mathrm{mM}$ IFKhAN-92. It is important to note that the mixture components show some indications of synergism at this temperature, while the $K_{\mathrm{m}}$ values for the cathodic and anodic processes are 4.1 and 1.8, respectively. The most efficient inhibition of electrode reactions by the mixed inhibitor was achieved by increasing $C_{\text {mix }}$ and the HA content in the mixture. For example, the $i_{\mathrm{c}}$ and $i_{\mathrm{a}}$ of steel are 10.3 and 4.2 times smaller, respectively, in 
the presence of the formulation containing $5.0 \mathrm{mM}$ IFKhAN-92+10.0 mM HA than in the presence of $5.0 \mathrm{mM}$ IFKhAN-92.

The use of formulations containing IFKhAN-92 provides efficient inhibition of both electrode reactions of mild steel in $\mathrm{HCl}$ solution even at $t=100^{\circ} \mathrm{C}$, where IFKhAN-92 used separately in an equivalent concentration does not provide any considerable effect on the electrode reactions on the metal.

\section{Sulfuric acid}

The $E_{\text {cor }}$ in $2.0 \mathrm{M} \mathrm{H}_{2} \mathrm{SO}_{4}$ is ennobled somewhat as $t$ increases (Table 2, Fig. 2). Like in $\mathrm{HCl}$ solution, the $b_{\text {a }}$ slope exceeds the theoretical value of $0.040 \mathrm{~V}$ [10], probably due to the formation of a sludge layer on the metal surface. Furthermore, $b_{\mathrm{a}}$ increases systematically with an increase in $t$ until $i_{\mathrm{d}}$ is reached. The abundant sludge formation and evolution of gaseous hydrogen observed on the electrodes increases the $b_{\mathrm{c}}$ slope until $i_{\mathrm{d}}$ is reached at $t \geq$ $60^{\circ} \mathrm{C}$. The $i_{\mathrm{c}}$ and $i_{\mathrm{a}}$ values increase with $t$, but these processes slow down considerably at $t>80^{\circ} \mathrm{C}$. A similar effect was observed for $2.0 \mathrm{M} \mathrm{HCl}$. The possible reasons of this effect were discussed above.

Table 2. Free corrosion potentials $\left(E_{\mathrm{cor}}\right)$, Tafel slopes $b_{\mathrm{c}}$ and $b_{\mathrm{a}}$, cathodic and anodic current densities $\left(i_{\mathrm{c}}\right.$ and $\left.i_{\mathrm{a}}\right)$, and inhibition coefficients for the cathodic and anodic reactions $\left(\gamma_{\mathrm{c}}\right.$ and $\left.\gamma_{\mathrm{a}}\right)$ of a steel cylinder in $2.0 \mathrm{M} \mathrm{H}_{2} \mathrm{SO}_{4}$ as a function of $t$ at $E=-0.300$ and $-0.100 \mathrm{~V}$, respectively.

\begin{tabular}{|c|c|c|c|c|c|c|c|c|}
\hline Inhibitor & $t,{ }^{\circ} \mathbf{C}$ & $E_{\text {corr, }}, \mathbf{V}$ & $b_{c}, \mathbf{V}$ & $b_{\mathbf{a}}, \mathbf{V}$ & $i_{\mathfrak{c}}, \mathbf{A} / \mathbf{m}^{2}$ & $i_{\mathrm{a}}, \mathbf{A} / \mathbf{m}^{2}$ & $\gamma_{\mathrm{c}}$ & $\gamma_{\mathrm{a}}$ \\
\hline- & \multirow{6}{*}{20} & -0.210 & 0.120 & 0.060 & 68.0 & 205 & - & - \\
\hline $5.0 \mathrm{mM}$ IFKhAN-92 & & -0.140 & $i_{\mathrm{d}}$ & 0.060 & 0.51 & 0.43 & 133 & 500 \\
\hline $5.0 \mathrm{mM} \mathrm{KI}$ & & -0.200 & 0.100 & 0.060 & 5.21 & 6.65 & 13.05 & 30.83 \\
\hline $5.0 \mathrm{mM} \mathrm{KBr}$ & & -0.220 & 0.120 & 0.060 & 50.5 & 121 & 1.35 & 1.69 \\
\hline $\begin{array}{l}2.5 \text { mM IFKhAN-92 } \\
+2.5 \text { mM KI }\end{array}$ & & -0.110 & $i_{\mathrm{d}}$ & 0.060 & 0.92 & 0.02 & 67.32 & 976 \\
\hline $\begin{array}{l}2.5 \text { mM IFKhAN-92 } \\
+2.5 \mathrm{mM} \mathrm{KBr}\end{array}$ & & -0.120 & $i_{\mathrm{d}}$ & 0.060 & 1.01 & 0.21 & 67 & 976 \\
\hline- & \multirow{6}{*}{40} & -0.210 & 0.120 & 0.060 & 386 & 569 & - & - \\
\hline 5.0 mM IFKhAN-92 & & -0.130 & $i_{\mathrm{d}}$ & 0.060 & 3.82 & 0.50 & 101 & 1138 \\
\hline $5.0 \mathrm{mM} \mathrm{KI}$ & & -0.200 & 0.100 & 0.060 & 22.5 & 14.3 & 17.16 & 41.7 \\
\hline $5.0 \mathrm{mM} \mathrm{KBr}$ & & -0.210 & 0.120 & 0.060 & 327 & 401 & 1.18 & 1.42 \\
\hline $\begin{array}{c}2.5 \text { mM IFKhAN-92 } \\
+2.5 \mathrm{mM} \mathrm{KI}\end{array}$ & & -0.130 & $i_{\mathrm{d}}$ & 0.060 & 3.56 & 0.32 & 108 & 1862 \\
\hline $\begin{array}{l}2.5 \mathrm{mM} \text { IFKhAN-92 } \\
\quad+2.5 \mathrm{mM} \mathrm{KBr}\end{array}$ & & -0.130 & $i_{\mathrm{d}}$ & 0.060 & 4.84 & 0.45 & 79.8 & 1324 \\
\hline
\end{tabular}


Table 2 (cont.)

\begin{tabular}{|c|c|c|c|c|c|c|c|c|}
\hline Inhibitor & $t,{ }^{\circ} \mathrm{C}$ & $E_{\text {corr }}, \mathbf{V}$ & $b_{c}, \mathbf{V}$ & $b_{\mathrm{a}}, \mathrm{V}$ & $i_{\mathrm{c}}, \mathbf{A} / \mathbf{m}^{2}$ & $i_{\mathrm{a}}, \mathbf{A} / \mathbf{m}^{2}$ & $\gamma_{\mathrm{c}}$ & $\gamma_{\mathrm{a}}$ \\
\hline- & \multirow{9}{*}{60} & -0.205 & 0.140 & 0.120 & 1219 & 795 & - & - \\
\hline $0.1 \mathrm{mM}$ IFKhAN-92 & & -0.205 & 0.120 & 0.060 & 629 & 795 & 1.94 & 1.00 \\
\hline 1.0 mM IFKhAN-92 & & -0.205 & 0.120 & 0.060 & 400 & 795 & 3.05 & 1.00 \\
\hline 5.0 mM IFKhAN-92 & & -0.145 & 0.120 & 0.060 & 86.5 & 1.65 & 14.1 & 482 \\
\hline $\begin{array}{c}10.0 \mathrm{mM} \text { IFKhAN- } \\
92\end{array}$ & & -0.190 & 0.120 & 0.090 & 20.1 & 1.20 & 60.7 & 622 \\
\hline $5.0 \mathrm{mM} \mathrm{KI}$ & & -0.200 & 0.120 & 0.060 & 171 & 24.3 & 7.12 & 32.7 \\
\hline $5.0 \mathrm{mM} \mathrm{KBr}$ & & -0.210 & 0.140 & 0.120 & 684 & 670 & 1.78 & 1.19 \\
\hline $\begin{array}{l}2.5 \text { mM IFKhAN-92 } \\
+2.5 \mathrm{mM} \mathrm{KI}\end{array}$ & & -0.140 & $i_{\mathrm{d}}$ & 0.060 & 11.7 & 0.51 & 104 & 1559 \\
\hline $\begin{array}{l}2.5 \mathrm{mM} \text { IFKhAN-92 } \\
\quad+2.5 \mathrm{mM} \mathrm{KBr}\end{array}$ & & -0.140 & 0.120 & 0.060 & 20.3 & 1.00 & 60.0 & 795 \\
\hline- & \multirow{6}{*}{80} & -0.200 & $i_{\mathrm{d}}$ & $i_{\mathrm{d}}$ & 2100 & 1750 & - & - \\
\hline 5.0 mM IFKhAN-92 & & -0.170 & 0.120 & 0.110 & 286 & 12.0 & 7.34 & 146 \\
\hline $5.0 \mathrm{mM} \mathrm{KI}$ & & -0.190 & 0.120 & 0.060 & 495 & 43.6 & 4.24 & 40.14 \\
\hline $5.0 \mathrm{mM} \mathrm{KBr}$ & & -0.190 & $i_{\mathrm{d}}$ & $i_{\mathrm{d}}$ & 1250 & 807 & 1.68 & 2.17 \\
\hline $\begin{array}{l}2.5 \text { mM IFKhAN-92 } \\
+2.5 \mathrm{mM} \mathrm{KI}\end{array}$ & & -0.220 & 0.120 & $i_{\mathrm{d}}$ & 122 & 13.7 & 17.2 & 128 \\
\hline $\begin{array}{c}2.5 \mathrm{mM} \text { IFKhAN-92 } \\
+2.5 \mathrm{mM} \mathrm{KBr}\end{array}$ & & -0.200 & $i_{\mathrm{d}}$ & $i_{\mathrm{d}}$ & 280 & 11.9 & 7.5 & 147 \\
\hline- & \multirow{7}{*}{100} & -0.190 & $i_{\mathrm{d}}$ & $i_{\mathrm{d}}$ & 2707 & 1780 & - & - \\
\hline 5.0 mM IFKhAN-92 & & -0.190 & $i_{\mathrm{d}}$ & $i_{\mathrm{d}}$ & 2572 & 1100 & 1.05 & 1.62 \\
\hline $5.0 \mathrm{mM} \mathrm{KI}$ & & -0.190 & 0.140 & 0.060 & 1550 & 296 & 1.75 & 6.03 \\
\hline $5.0 \mathrm{mM} \mathrm{KBr}$ & & -0.180 & $i_{\mathrm{d}}$ & $i_{\mathrm{d}}$ & 2333 & 1604 & 1.16 & 1.11 \\
\hline $\begin{array}{l}2.5 \mathrm{mM} \text { IFKhAN-92 } \\
+2.5 \mathrm{mM} \mathrm{KI}\end{array}$ & & -0.230 & 0.120 & $i_{\mathrm{d}}$ & 600 & 72.4 & 4.5 & 24.6 \\
\hline $\begin{array}{l}2.5 \mathrm{mM} \text { IFKhAN-92 } \\
+2.5 \mathrm{mM} \mathrm{KBr}\end{array}$ & & -0.200 & $i_{\mathrm{d}}$ & $i_{\mathrm{d}}$ & 1870 & 822 & 1.45 & 2.17 \\
\hline $\begin{array}{l}5.0 \mathrm{mM} \text { IFKhAN-92 } \\
\quad+10.0 \mathrm{mM} \mathrm{KBr}\end{array}$ & & -0.180 & 0.120 & $i_{\mathrm{d}}$ & 242 & 13.5 & 11.2 & 132 \\
\hline
\end{tabular}



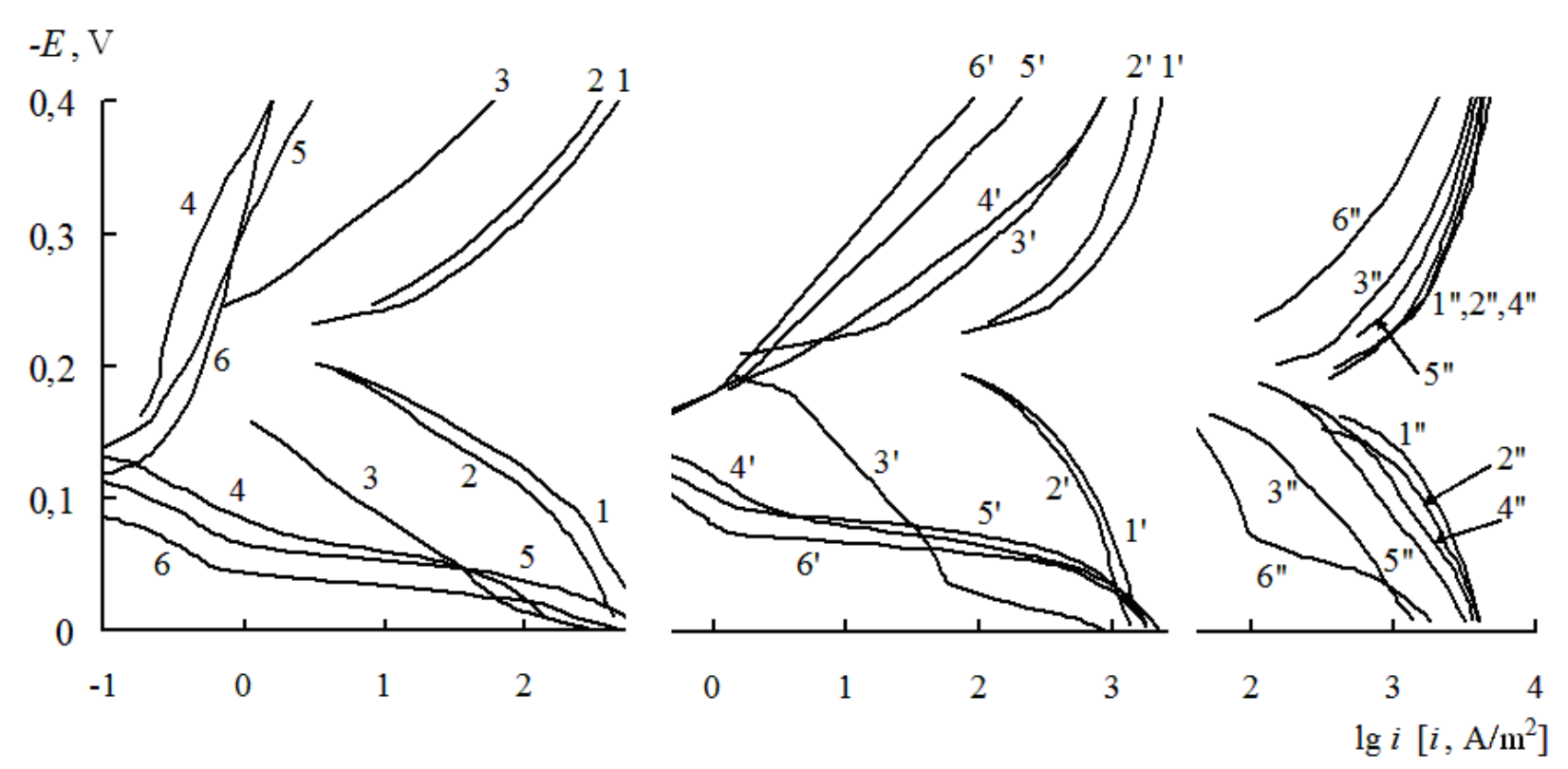

Fig. 2. Polarization curves of a steel cylinder in $2.0 \mathrm{M} \mathrm{H}_{2} \mathrm{SO}_{4}\left(1, l^{\prime}, l^{\prime}\right.$ ' ') containing $5.0 \mathrm{mM}$ $\operatorname{KBr}(2,2$ ', 2', '), 5.0 mM KI (3, 3', 3', '), 5.0 mM IFKhAN-92 (4, 4', 4','), 2.5 mM IFKhAN-92 $+2.5 \mathrm{mM} \operatorname{KBr}\left(5,5^{\prime}, 5^{\prime},\right)$, or $2.5 \mathrm{mM}$ IFKhAN-92 + $2.5 \mathrm{mM} \mathrm{KI}\left(6,6^{\prime}, 6^{\prime \prime}\right)$ at temperatures, 'C: $25-1,2,3,4,5,6 ; 60-1$ ', 2', 3', 4', 5', 6'; $100-1$ ', 2,', 3', 4', 5', 6',

The addition of $5.0 \mathrm{mM}$ IFKhAN-92 preferentially slows down the anodic reaction of steel $\left(t=20-80^{\circ} \mathrm{C}\right)$. This is indicated by an increase in $E_{\text {cor }}$ of steel by $0.030-0.080 \mathrm{~V}$ in comparison with the acid solution. The $E_{\text {cor }}$ values of steel at $t=100^{\circ} \mathrm{C}$ are the same both in the presence and in the absence of IFKhAN-92 in the acid solution. The $b_{\text {a }}$ slope increases systematically with an increase in $t$ from $0.060 \mathrm{~V}$ up to the potential where $i_{\mathrm{d}}$ starts. In the entire temperature range, the cathodic process occurs under diffusion control due to the formation of a protective film on steel by the inhibitor. At $t=20-80^{\circ} \mathrm{C}$, addition of $5.0 \mathrm{mM}$ IFKhAN-92 has an inhibiting effect on the cathodic and anodic reactions on steel, but the decrease in the $\gamma_{\mathrm{c}}$ and $\gamma_{\mathrm{a}}$ coefficients that starts at $t=60^{\circ} \mathrm{C}$ ends in a nearly complete loss of the protective effect by the inhibitor at $t=100^{\circ} \mathrm{C}$. It has been shown at $t=$ $60^{\circ} \mathrm{C}$ that an increase in the inhibitor concentration enhances the inhibition of steel electrode reactions. This enhancement is the strongest $(Z \geq 90 \%)$ at $C_{\text {IFKhAN-92 }} \geq 5.0 \mathrm{mM}$.

Iodides and bromides are efficient additives that enhance the protective effect of nitrogen-containing inhibitors in media containing sulfuric acid [3]. Addition of $5.0 \mathrm{mM}$ KI slows down both electrode reactions of steel; the maximum $\gamma_{c}$ and $\gamma_{a}$ values are observed at $t=40^{\circ} \mathrm{C}$. An equimolar additive of $\mathrm{KBr}$ nearly does not hinder the cathodic and anodic reactions under the same conditions.

The presence of the formulation containing $2.5 \mathrm{mM}$ IFKhAN-92 $+2.5 \mathrm{mM} \mathrm{KI}$ in an $\mathrm{H}_{2} \mathrm{SO}_{4}$ solution affects $E_{\text {cor }}$ considerably. It is higher by $0.065-0.100 \mathrm{~V}$ than in the acid itself in the range of $t=20-60^{\circ} \mathrm{C}$ but lower by $0.020-0.040 \mathrm{~V}$ at higher temperatures. The cathodic reaction, as well as the anodic reaction at $t \geq 80^{\circ} \mathrm{C}$, occur in the diffusion mode. At $t=40-100^{\circ} \mathrm{C}$, this mixture inhibits the electrode processes more efficiently than 
5.0 mM IFKhAN-92. Its important property is that it still has a protective effect on the electrode reactions at $t=100^{\circ} \mathrm{C}$, whereas IFKhAN-92 itself loses this capability. A synergism between the effects of the mixture components is observed at this temperature; the $K_{\mathrm{m}}$ values for the cathodic and anodic processes are 2.4 and 2.5, respectively.

The mixture containing $2.5 \mathrm{mM}$ IFKhAN-92 $+2.5 \mathrm{mM} \mathrm{KBr}$ is much less efficient in the inhibition of the electrode reactions. Similarly to the mixture containing KI, $E_{\text {cor }}$ is by $0.065-0.090 \mathrm{~V}$ more positive in the range of $t=20-60^{\circ} \mathrm{C}$ than in the reference solution. It is only at $t=20-60^{\circ} \mathrm{C}$ that this inhibitor formulation hinders the anodic process more efficiently than a similar amount of IFKhAN-92 alone. It is inferior or comparable to IFKhAN-92 in terms of slowing down the cathodic process. However, by increasing the concentration of this mixture and increasing the content of $\mathrm{KBr}$ therein, it is possible to hinder the electrode reactions on steel even at $t=100^{\circ} \mathrm{C}$. In the presence of $5.0 \mathrm{mM}$ IFKhAN-92 $+10.0 \mathrm{mM} \mathrm{KBr}$, the $\gamma_{\mathrm{c}}$ and $\gamma_{\mathrm{a}}$ values are 10.7 and 81.5 times higher than in a solution containing $5.0 \mathrm{mM}$ IFKhAN-92 only.

Thus, electrochemical studies show that on mild steel in $\mathrm{HCl}$ and $\mathrm{H}_{2} \mathrm{SO}_{4}$ solutions, and sometimes in the presence of an inhibitor as well, the flow of electrochemical reactions is considerably altered by the formation of a sludge layer on the metal surface and evolution of gaseous hydrogen. The sludge layer and the hydrogen bubbles that continuously appear on the metal surface shield the metal surface, thus hindering the access of protons to it and removal of soluble reaction products, and making the process subject to diffusion limitations. An increase in temperature accelerates the sludge formation and the formation rate of gaseous hydrogen, hence the effect of these processes on the electrode reactions on steel increases. As a result, the cathodic and anodic reactions in solutions of the acids themselves slow down considerably at $t=100^{\circ} \mathrm{C}$.

The addition of IFKhAN-92 inhibitor to $2.0 \mathrm{M} \mathrm{HCl}$ or $\mathrm{H}_{2} \mathrm{SO}_{4}$ allows the electrode reactions on mild steel to be hindered at $t \leq 80^{\circ} \mathrm{C}$, but this effect is not observed at higher $t$ values. If IFKhAN-92 is used jointly with $\mathrm{HA}$ in $\mathrm{HCl}$ solutions or with $\mathrm{KI}$ or $\mathrm{KBr}$ in $\mathrm{H}_{2} \mathrm{SO}_{4}$ solutions, the steel electrode reactions can be slowed down at temperatures up to $100^{\circ} \mathrm{C}$. In this case, compositions of IFKhAN-92 with a higher content of an additive appear to be the most efficient. Unfortunately, electrochemical studies to identify the effect of IFKhAN-92 based formulations on the steel electrode reactions at $t>100^{\circ} \mathrm{C}$ are highly complicated from the technical viewpoint. However, the results of studies obtained to date allow us to hope that inhibition of steel electrode reactions by IFKhAN-92 based formulations that we developed would also occur at higher $t$ values and would thus provide corrosion protection of steel under these conditions.

It should be noted that the $\gamma$ values for the steel electrode reactions observed in the presence of inhibitors are considerably lower, especially at elevated temperatures, since the cathodic and anodic processes in the reference solutions are hindered considerably by the sludge formed on the metal surface and by the gaseous hydrogen evolved. The real $\gamma$ values of the electrode reactions should not be lower than those we obtained. The corrosion process occurs at $E_{\text {cor }}$, where the rates of both reactions are considerably smaller than those 
under cathodic or anodic polarization, and hence sludge formation and hydrogen evolution on the metal surface are slower. It can be assumed that the hindering effect of these side processes on the overall corrosion rate in the case of corrosion in the reference solutions at $E_{\text {cor }}$ would be lower and the protective effect of inhibitors would be higher.

Experimental data on efficient inhibition of steel electrode reactions in $2.0 \mathrm{M} \mathrm{HCl}$ and $\mathrm{H}_{2} \mathrm{SO}_{4}$ by IFKhAN-92 and formulations based on it suggest that it can be used for the protection of mild steel in solutions of these acids at $t \leq 80^{\circ} \mathrm{C}$, or at least up to $t=100^{\circ} \mathrm{C}$ by inhibitor formulations. This assumption can be confirmed by gravimetric measurements of the corrosion rate of steel in $\mathrm{HCl}$ and $\mathrm{H}_{2} \mathrm{SO}_{4}$ solutions without and with the inhibitor and formulations on its basis in the temperature range studied.

\section{Corrosion studies}

The corrosion rates of steel 20 in $2.0 \mathrm{M} \mathrm{HCl}$ and $\mathrm{H}_{2} \mathrm{SO}_{4}$ increase with $t$ (Fig. 3). In the $\mathrm{HCl}$ solution, a $t$ increase by $160^{\circ} \mathrm{C}$ results in a 3100 -fold increase in $k$. This process occurs somewhat more slowly in $\mathrm{H}_{2} \mathrm{SO}_{4}$ : even a $t$ increase by $200^{\circ} \mathrm{C}$ increases $k 1610$-fold.

Inhibition of steel 20 corrosion in $2.0 \mathrm{M} \mathrm{HCl}$ by IFKhAN-92 becomes stronger as $t$ increases to $80^{\circ} \mathrm{C}$ (Fig. 4). Though higher concentrations, $C_{\mathrm{IFKhAN}-92}=10.0$ and $20.0 \mathrm{mM}$, were used to perform the corrosion tests, the $\gamma$ value decreased at least twofold on transition to $t>80^{\circ} \mathrm{C}$. A decrease in the protective effect of the $10.0 \mathrm{mM}$ IFKhAN-92 + $10.0 \mathrm{mM}$ HA formulation starts only above $120^{\circ} \mathrm{C}$, where $\gamma$ decreases abruptly 8.3 -fold. At $t \geq 20^{\circ} \mathrm{C}$, the protective effect of this formulation is higher than that for an equimolar amount of IFKhAN-92 alone. By increasing the content of the formulation being studied in solution and by increasing the fraction of HA in the formulation, mild steel can be protected even at $t=160^{\circ} \mathrm{C}$. It is interesting that the HA additive itself does not slow down steel corrosion considerably.

As the temperature increases, the protective effect of IFKhAN-92 in $2.0 \mathrm{M} \mathrm{H}_{2} \mathrm{SO}_{4}$ reaches a maximum at $100^{\circ} \mathrm{C}$, then decreases (Fig. 5, 6). At $C=20.0 \mathrm{mM}$, IFKhAN-92 inhibits steel corrosion much more strongly than at a lower concentration $(C=10.0 \mathrm{mM})$. In contrast, the protective effect of $5.0 \mathrm{mM}$ IFKhAN-92 +5.0 mM KI is retained at rather a high level up to $160^{\circ} \mathrm{C}$, while the maximum $\gamma$ is reached at a $t$ no lower than $120^{\circ} \mathrm{C}$. Mild steel can even be protected at temperatures up to $200^{\circ} \mathrm{C}$ by a mixture of $10.0 \mathrm{mM}$ IFKhAN-92 $+5.0 \mathrm{mM} \mathrm{KI}$. Steel protection by KI alone is only possible at $t \leq 100^{\circ} \mathrm{C}$.

The mixture of IFKhAN-92 with $\mathrm{KBr}$ is inferior in protective capability to the formulation containing KI. A mixture of $10.0 \mathrm{mM}$ IFKhAN-92 $+10.0 \mathrm{mM} \mathrm{KBr}$ should be used to achieve a good protective effect at $t \leq 160^{\circ} \mathrm{C}$. Furthermore, the maximum $\gamma$ value is observed at $t=100^{\circ} \mathrm{C}$, which is lower than that for the iodide-containing formulation. A mixture of $20.0 \mathrm{mM}$ IFKhAN-92 $+20.0 \mathrm{mM} \mathrm{KBr}$ can be used to protect steels at $t \leq 200^{\circ} \mathrm{C}$. 


\section{$k, \mathrm{~kg} /\left(\mathrm{m}^{2} \cdot \mathrm{h}\right)$}

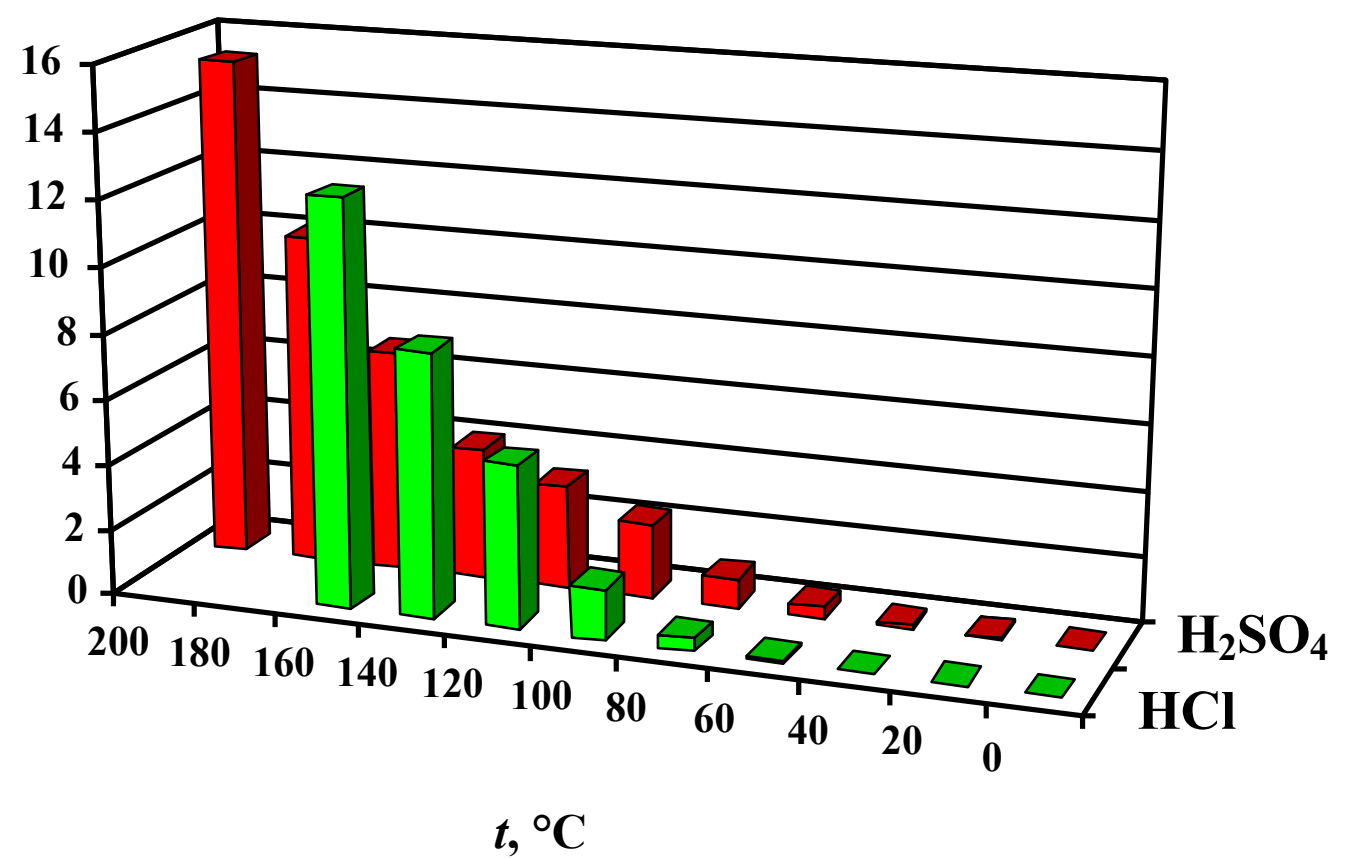

Fig. 3. Corrosion rates of steel 20 in $2.0 \mathrm{M} \mathrm{HCl}$ and $\mathrm{H}_{2} \mathrm{SO}_{4}$ as a function of temperature. Test duration: $0.5 \mathrm{~h}$.

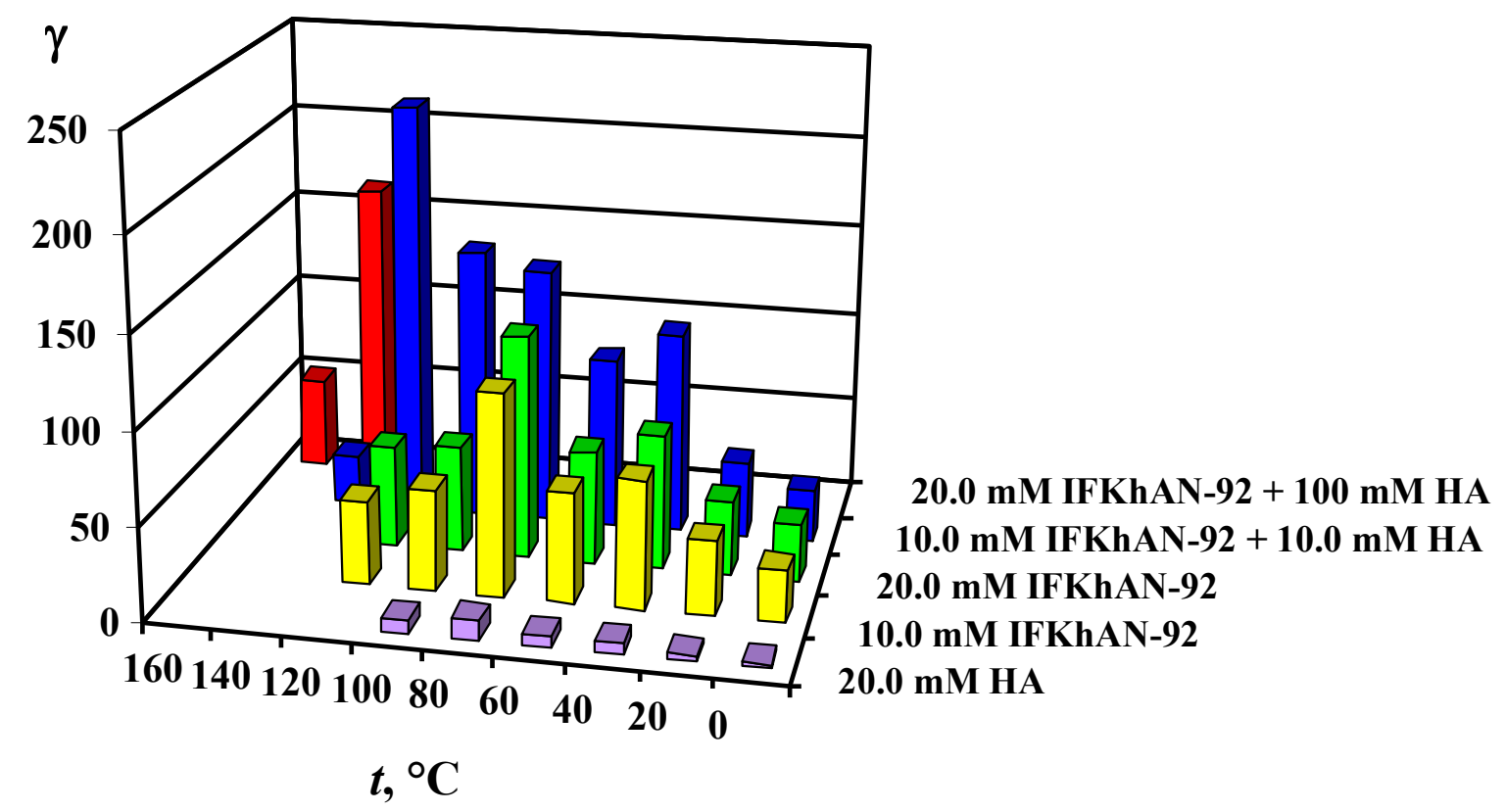

Fig. 4. Inhibition coefficients of steel 20 corrosion in $2.0 \mathrm{M} \mathrm{HCl}$ by IFKhAN-92, HA additive, and their combinations. Test duration: $0.5 \mathrm{~h}$. 


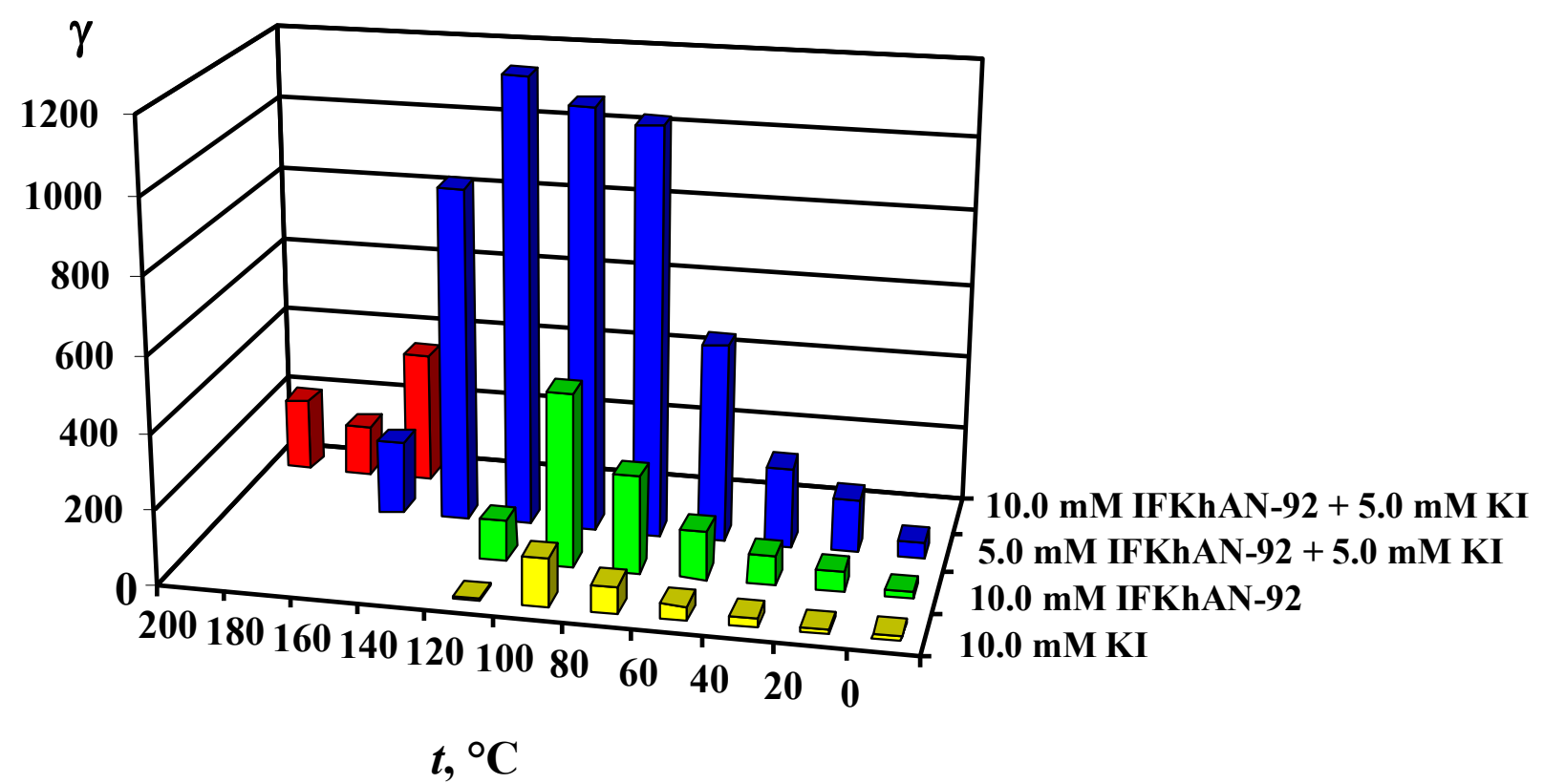

Fig. 5. Inhibition coefficients of steel 20 corrosion in $2.0 \mathrm{M} \mathrm{H}_{2} \mathrm{SO}_{4}$ by IFKhAN-92, KI, and their combinations. Test duration: $0.5 \mathrm{~h}$.

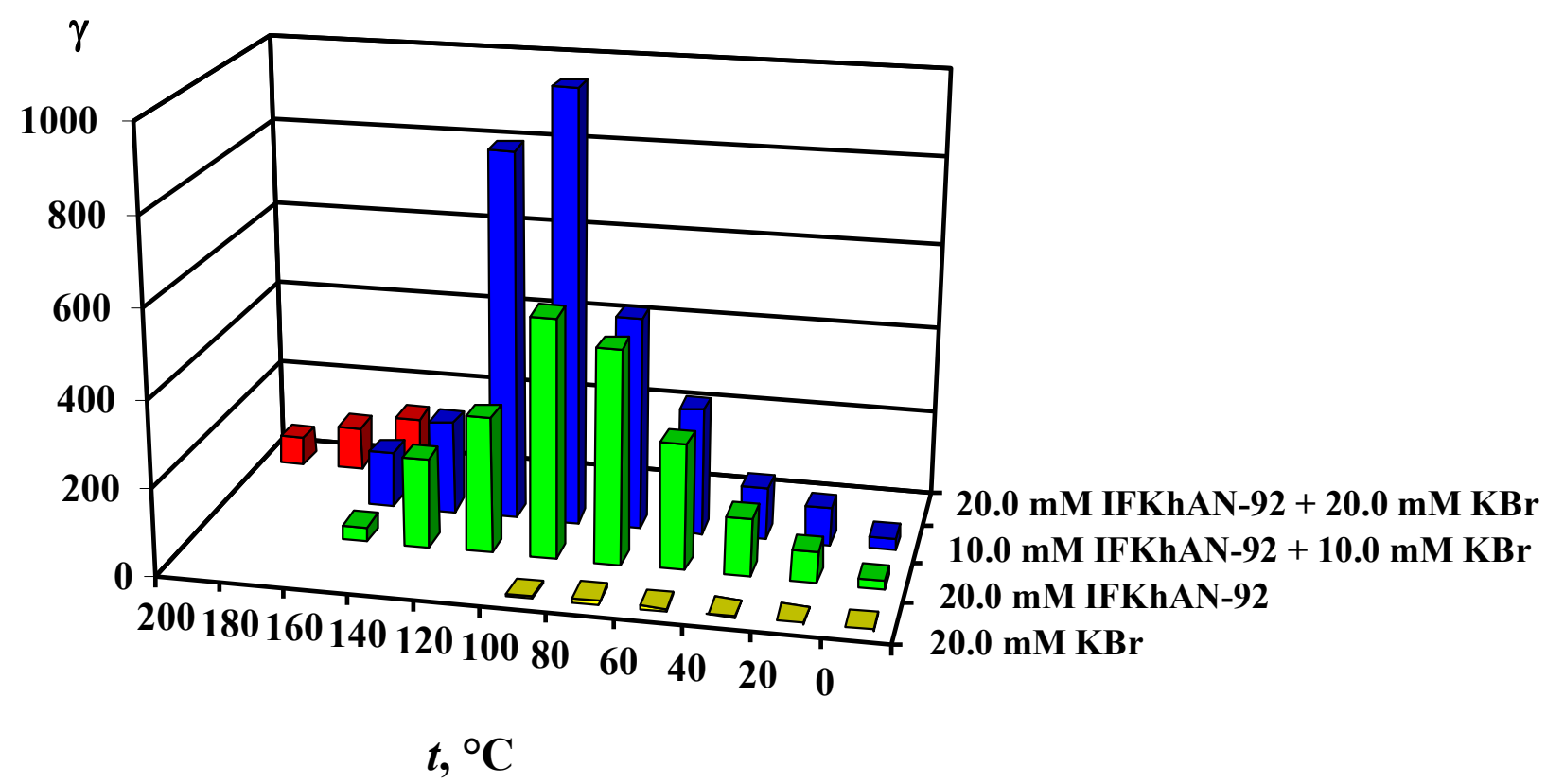

Fig. 6. Inhibition coefficients of steel 20 corrosion in $2.0 \mathrm{M} \mathrm{H}_{2} \mathrm{SO}_{4}$ by IFKhAN-92, $\mathrm{KBr}$, and their combinations. Test duration: $0.5 \mathrm{~h}$.

Though the protective effect of IFKhAN-92 based mixtures decreases at $t$ values exceeding the maximum efficiency temperatures, they slow down mild steel corrosion to a reasonable extent even under these conditions. For example, for steel 20 at $t=140^{\circ} \mathrm{C}$ in 
2.0 M HCl $+10.0 \mathrm{mM}$ IFKhAN-92 $+10.0 \mathrm{mM} \mathrm{HA}$ solution, $k \leq 50 \mathrm{~g} /\left(\mathrm{m}^{2} \cdot \mathrm{h}\right)$ against $k=$ $8060 \mathrm{~g} /\left(\mathrm{m}^{2} \cdot \mathrm{h}\right)$ in the non-inhibited acid. A better result can be achieved in $2.0 \mathrm{M} \mathrm{H}_{2} \mathrm{SO}_{4}$ solution containing $10.0 \mathrm{mM}$ IFKhAN-92 $+5.0 \mathrm{mM}$ KI. This mixture decreases $k$ to $78.4 \mathrm{~g} /\left(\mathrm{m}^{2} \cdot \mathrm{h}\right)$ against $15300 \mathrm{~g} /\left(\mathrm{m}^{2} \cdot \mathrm{h}\right)$ observed in the reference solution. Though the efficiency of IFKhAN-92 mixtures with $\mathrm{KBr}$ in $2.0 \mathrm{M} \mathrm{H}_{2} \mathrm{SO}_{4}$ is lower than with $\mathrm{KI}$, both of them improve the protective effect of IFKhAN-92 at $t \leq 160^{\circ} \mathrm{C}$ considerably. However, the cost of $\mathrm{KBr}$ is considerably lower than that of $\mathrm{KI}$, which is very important for the practical application of the inhibitor.

The data that we obtained on the inhibition of mild steel corrosion in $2.0 \mathrm{M} \mathrm{HCl}$ and $\mathrm{H}_{2} \mathrm{SO}_{4}$ by formulations based on IFKhAN-92 indirectly confirm the assumption made above that the inhibitive effect of IFKhAN-92 mixtures with $\mathrm{HA}, \mathrm{KI}$ and $\mathrm{KBr}$ on steel electrode reactions can be retained at $t>100^{\circ} \mathrm{C}$. A good qualitative match is observed between the effect of IFKhAN-92 and mixtures based thereon on the electrode reactions of steel and its corrosion behavior. Moreover, the results of corrosion tests were found to be not worse, and in certain cases much better, than those predicted from electrochemical studies. However, we have already predicted that corrosion tests may show higher inhibition efficiency due to the discovered effect that the electrode reaction rates in reference solutions are underestimated at $t$ values approaching $100^{\circ} \mathrm{C}$.

\section{Conclusions}

1. The IFKhAN-92 inhibitor slows down the electrode reactions of mild steel in $2.0 \mathrm{M} \mathrm{HCl}$ and $\mathrm{H}_{2} \mathrm{SO}_{4}$ solutions at temperatures up to $80^{\circ} \mathrm{C}$.

2. The use of the IFKhAN-92 inhibitor in combination with $\mathrm{HA}$ in $2.0 \mathrm{M} \mathrm{HCl}$ or with $\mathrm{KI}$ or $\mathrm{KBr}$ in $2.0 \mathrm{M} \mathrm{H}_{2} \mathrm{SO}_{4}$ expands the temperature range of efficient inhibition of the cathodic and anodic reactions of mild steel at least up to $100^{\circ} \mathrm{C}$. A considerable improvement in the inhibition of both electrode reactions can be achieved by increasing the total concentration of the mixture and the content of the additive in it.

3. The efficient hindrance of electrode reactions by mixed inhibitors based on IFKhAN-92 allows steel protection to be provided up to $160^{\circ} \mathrm{C}$ in $2.0 \mathrm{M} \mathrm{HCl}$ and up to $200^{\circ} \mathrm{C}$ in $2.0 \mathrm{M} \mathrm{H}_{2} \mathrm{SO}_{4}$.

\section{References}

1. Yu. I. Kuznetsov and L. P. Kazansky, Russian Chemical Reviews, 2008, 77, no. 3, 219.

2. Ya. G. Avdeev and Yu. I. Kuznetsov, Russian Chemical Reviews, 2012, 81, no. 12, 1133.

3. Ya. G. Avdeev, P. A. Belinskii, Yu. I. Kuznetsov and O. O. Zel', Korroz.: mater., zasch., 2008, no. 8, 16 (in Russian).

4. Ya. G. Avdeev, L. V. Frolova, Yu. I. Kuznetsov and O.O. Zel', Korroz.: mater., zasch., 2010, no. 5, 22 (in Russian).

5. Ya. G. Avdeev, L. V. Frolova, Yu. I. Kuznetsov and O. O. Zel', Korroz.: mater., zasch., 2010, no. 8, 19 (in Russian). 
6. Ya. G. Avdeev and Yu. I. Kuznetsov, Korroz.: mater., zasch., 2011, no. 5, 30 (in Russian).

7. Ya. G. Avdeev, P. A. Belinskii, Yu. I. Kuznetsov and O. O. Zel', Protection of Metals and Physical Chemistry of Surface, 2010, 46, no. 7, 782.

8. Ya. G. Avdeev, A. Yu. Luchkin, Yu. I. Kuznetsov, L. P. Kazansky and Yu. E. Pronin, Korroz.: mater., zasch., 2012, no. 11, 20 (in Russian).

9. Yu. I. Kuznetsov, Russian Chemical Reviews, 2004, 73, no. 1, 75.

10. S. M. Reshetnikov, Ingibitory kislotnoi korrozii metallov (Metal Corrosion Inhibitors in Acids), Khimiya, Leningrad, 1986, pp. 6-25 (in Russian). 